\title{
"It Helps if You Think of Yourself as a Radio Presenter!" A Lefebvrian Commentary on the Concerns, Conflicts and Opportunities of Online Block Teaching
}

\author{
Ben Harkin, \\ Chrissi Nerantzi
}

\section{Manchester Metropolitan University, UK}

\begin{abstract}
The COVID-19 pandemic has generated shifts in how higher education provision is offered. In one UK institution block teaching was introduced. This way of teaching and learning has brought new challenges and opportunities for staff and students. To date, little research or theoretical discussion has investigated how this hybrid approach or differences between tutors and student can arise in the use of online teaching spaces (OTS) within a block-teaching format. The present paper focuses on the institutionwide implementation of an online block-teaching model at Manchester Metropolitan University in the United Kingdom. With a specific emphasis on observations and reflections on the experiences of undergraduate students' and staff by one of the authors from the Department of Psychology who employed an online block teaching approach (6 weeks) from the beginning of block 1 during the academic year 2020/21. We provide a novel methodological advancement of Lefebvre's (1991) Trialectic of Space to discuss how students and tutors jointly produce and experience learning and teaching within an online block teaching approach. Pre-existing behavioural, cognitive and emotional experiences of using online spaces, contribute to the curriculum, student-tutor and student-student dialogue. We also highlight the importance of community within an online block teaching approach. Applications of the Lefebvrian model (1991) to present pedagogical approaches along with avenues of future research are considered.
\end{abstract}

Keywords: Online block teaching, Lefebvre's Trialectic, Online learning, Student engagement, Student-Tutor dissonance, Community 


\section{Introduction}

The shift to an online block-teaching model, with a shorter than the normal term or semester, in response to COVID-19 guidelines brought rapid changes to teaching and learning that have had an impact on the students' and staff experiences. Its uniqueness is further reflected in the fact that little to no research has investigated the impact of such hybrid approaches on the students and tutors working within them. Block teaching is defined as an intensive mode of delivery, as it is "accelerated", "compressed", and "involves fewer contact hours" and so contrasts with 'traditional' semesterised teaching approaches (Davies, 2006). It involves a specific number of weeks (e.g., six at Manchester Met) being devoted to a particular unit (i.e., at Manchester Met it is a 30 credit unit or two 15 credit units) topic and associated set of learning objectives (International Bureau of Education, 2020), and normally with a single assessment at the end of the block (Sewagegn and Diale, 2019).

However, research is equivocal on the overall benefits of intensive delivery. Advantages have been observed with respect the quality of the relationships between students and tutors, improved attendance and student perceptions of their own engagement (Swain, 2016). In contrast, discrepant findings of the block approach are observed in better (Boddy, 1986), similar (Messina, 1996) and worse (for review see Dickson et al., 2010) academic performance of students. Students have also identified issues with respect the quality and depth of their own learning, and potential mismatches between previous learning experiences; e.g., in primary, secondary school and previous traditionally semesterised years in university (Sewagegn and Diale, 2019). Student's within intensive approaches have reported concerns with workload (Loton, Stein, Parker, and Weaven, 2020) which is consistent with cognitive overload and exhaustion associated this mode of delivery (Male et al., 2016).

Similarly, tutors have voiced mixed perceptions regarding block teaching, with clear challenges identified (Kaya and Aksu, 2016). For example, Sewagegn and Diale (2019) stated that "intensive [block] teaching formats require careful organisation, adequate preparation, and varied teaching approaches" (p.3). This is particularly an issue when tutors have limited time to prepare materials and find themselves dealing with the demands of an online teaching space (OTS) for the first time. Indeed, maintaining a high level of stimulating materials may be stressful, especially when some tutors may find it difficult to "maintain energy due to the short-term and intense format of the block courses"(Sewagegn and Diale, 2019, p. 2) along with the demands of using novel digital technology (JISC, 2020). This suggests that block teaching may become fatiguing for both students and tutors. Interestingly, Dixon and O'Gorman (2020) highlighted that while some research does exist on the impact of block teaching from the students perspective, "somewhat overlooked [is] the impact such a structure has on those [tutors] tasked with delivering it" (p. 584).

Thus, students and tutors within the Department of Psychology at Manchester Met, who are less familiar or experienced with the delivery of online and/or distance education (versus the Open University; Online Conversion Courses for example) now find themselves operating in a new and under researched pedagogical space(JISC,

International Journal of Management and Applied Research, 2021, Vol. 8, No. 1 
"It Helps if You Think of Yourself as a Radio Presenter!" A Lefebvrian Commentary on the Concerns, Conflicts and Opportunities of Online Block Teaching

2020). A space that comprises a novel, complex and multifaceted mix of: (a) an online blocked teaching format; (b) Moodle (or similar platforms) to offer asynchronous activities; and (c) Microsoft (MS) Teams (or similar platforms) to facilitate synchronous learning activities. It is important to note that Manchester Met supports both these platforms.

Figure 1.Our modified version of Lefebvre's Trialectic of Space (1991), as applied to The Produced Online Teaching Space.

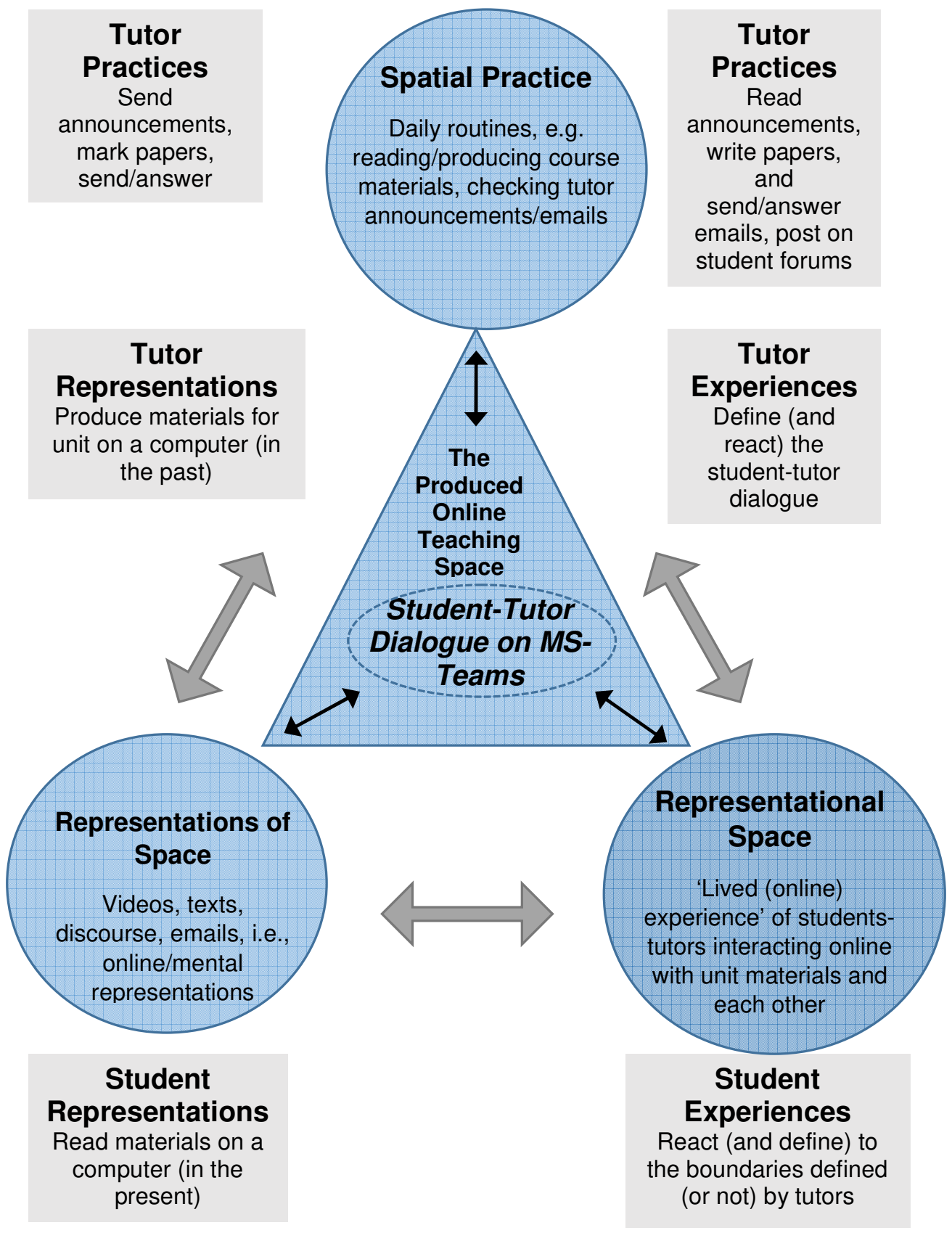

International Journal of Management and Applied Research, 2021, Vol. 8, No. 1 
Second, as a point of clarity, MS-Teams is a proprietary business communication platform with synchronous and asynchronous features. It offers chat facilities, screen/document sharing, videoconferencing, file storage, and application integration (Warren, 2016).Considering the above, the present paper will discuss student-tutor and student-student dialogue and causes of dissonance within the online block-teaching format. To understand this better, we provide a novel methodological advancement of Lefebvre's (1991) Trialectic of Space (see Figure 1) to discuss how students and tutors engage in and experience learning and teaching within an online teaching block approach. The benefits of looking at the online teaching space in this way was noted by Leston-Bandeira (2020) who stated that if we "consider the online space as a new space, and ... online learning as a new mode of learning" then "you'll start ... [to get] a feel for what needs to be done to guide your student's in their learning" (p.1).

\section{Lefebvre's (1991) Trialectic of Space and Online Block Teaching}

Lefebvre's Trialectic of Space (1991) presents an understanding of physical, mental and social aspects of human experience within a produced social space. Lefebvre's triad has been previously applied to understand how people produce space in cultural geography (leisure/tourism, Bunce, 2008; urban policy planning, Carp, 2008; social production of harmful practice, Parkin and Coomber, 2011), and virtual space (Kosari and Amoori, 2018). Lefebvre (1991) saw space not as a passive container but rather as an active arena that interacts with and produces thought and behaviour; i.e., the produced social space. It is the 'production' of space rather than the space per se that is the fundamental object of interest and so with the production of an online space comes consequences on physical space. To account for this, Lefebvre integrated physical, mental and social space to unify the main elements of the produced space, which in spatial terms he referred to as 'Spatial Practice', 'Representations of Space' and 'Representational Space', respectively (Lefebvre, 1991, p. 40). For clarity, we define the OTS as a messy amalgam of information related to a given teaching unit. For example, (a) emails and announcements; (b) learning materials, e.g., lectures, PowerPoint slides, videos; (c) asynchronous learning activities (i.e., completed individually before the workshop); and (d) synchronous learning activities completed in MS Teams.

In taking this perspective, the aim is to show that the OTS is not just a mechanical and inanimate space that we dip in and out of but rather is a virtual space that forms an extension of and blends in with our behaviours, thoughts and experiences(Saunders, Rutkowski, van Genuchten, Vogel, and Orrego, 2011). Whether we mean to or not, we project our own internal representations and expectations onto a given OTS and this occurs without the social cues, boundaries and roles that we experience in face-to-face communication; e.g., seminar room, laboratory, studio or lecture theatre. As a result, the OTS can potentially escalate conflict, confusion and anxiety likely already present in face-to-face settings. As noted by Kosari and Amoori (2018), who viewed the interaction of people within an online space as "the confrontation of the user[s] with real, virtual and borderline spaces as well as their lived experiences" [italics added] (p. 163). Such factors may in part explain why student's show lower rates of persistence for online compared to traditional face-to-face teaching (Yang, Baldwin and Snelson,

International Journal of Management and Applied Research, 2021, Vol. 8, No. 1 
2017). In the present paper, we will explore the potential exacerbation of such tensions within a block teaching approach.

The shift to an online approach will likely increase tutors' awareness of such miscommunication and even confrontation, which is useful for tutors to be aware of as it will likely impact the quality of the dialogue that occurs within OTSs. It is suggested that the online experience, if not designed with a scaffold that is supportive and inclusive, can result in a degree of conflict and dissonance at an implicit (e.g., misinterpreting the tone of emails; live chat) or explicit level. It is important to consider in our teaching that we are interpersonal and phenomenological beings not necessarily suited to communicate only via online modes and within online spaces(Kosari and Amoori, 2018). This concurs with research that showed community presence, activities, choice and tutor support are important means to create a collaborative online learning framework and to encourage students to make most effective use of online technology (Nerantzi, 2017). As highlighted by LestonBandeira (2020) we agree that fostering a strong sense of community is a critical feature to effective learning in an online context, and so we explore its importance throughout this paper.

It becomes apparent that the successful navigation of online spaces requires a unique skill set. Although how we use such skills is not always explicit, and adding to this complexity, we tend to engage with online platforms/information in a habitual and repetitive manner. For example, consider the situation of having a student who has limited to no experience of navigating online platforms such as Moodle or MS Teams and contrast this to the learnt and subsequently automatic behaviours of the experienced user. Indeed, we commonly observe that when the abilities of students fail to match the demands of the online space (i.e., a student failing to navigate Moodle in the opening week of a course), anxiety or even task avoidance/drop-out may follow (Proctor, 2017). Further issues (e.g., digital inequalities, cognitive overload) of online learning were highlighted by Nerantzi and Chatzidamianos (2020), who stated that "while the aim [of online teaching] is to be inclusive, inadvertently the design may create barriers for learning and is exclusive" (p. 487 ).

Our observations are further supported by the recent Student Digital Experiences Insight Survey (Killen and Langer-Crame, 2020) who noted that 54\% of students enjoyed trying out new and innovative technologies, while only $43 \%$ felt comfortable using mainstream technologies. This suggests that on a National level, approximately $50 \%$ of students are not entirely comfortable in using online technologies(Killen and Langer-Crame, 2020). A similar finding relates to tutors as well, wherein a large majority possessed limited online skills or experience at the beginning of lockdown (JISC, 2020). A discrepancy that is quickly picked up on by students: "When lecturers are forced to use technology they are not already familiar with it decreases the quality of the teaching" (Killen and Langer-Crame, 2020, p. 11). These points are particularly relevant to block teaching, as students and tutors have even a shorter time-period (vs. traditional semesterised teaching) to get up to speed in using and feeling comfortable with new online technologies.

International Journal of Management and Applied Research, 2021, Vol. 8, No. 1 
It is important to note that the use of online spaces is not by default negative. For example, viewing self-relevant information increases positive self-surveillance (Katz and Crocker, 2015), optimal self-presentation can stabilise self-perception (Tiidenberg and Cruz, 2015) and improve self-esteem (Gonzales and Hancock, 2011). Furthermore, internet use is reported to have a positive effect with individuals with low mental and emotional wellbeing (Bargh and McKenna, 2004) and social networking and online social proficiency has some application in the real world (Bouchillon, 2020).

Considering the above, we will first define each arm of Lefebvre's Trialectic as applied to the OTS. Then, we will identify how tutors and students simultaneously create and engage with the OTS in a block-teaching context via their own unique spatial practices, representations of space and representational space. In doing so we will highlight how such an approach can influence the nature and quality of studenttutor and student-student dialogue in the OTS; e.g., within sessions on MS Teams.

\section{Spatial practice and the online block teaching space}

'Spatial Practice' exists in people's habits, rituals, and patterns of movement that they adopt in space (Lefebvre, 1991). Spatial practices explain the manner in which daily routines are "concretized over time" (Urry, 1995, p. 25) via repetition in the space they occur.

When applied to an OTS in a block-teaching context, spatial practice represents the manner in which easy access via ever-present digital devices (e.g., personal computers, mobile phones, and tablets) encourages habitual interaction with content online, for example, learning materials, checking emails (e.g., to address questions about assessments), forums, MS Teams chat, etc. In turn, these devices employ 'digital spaces', which refers to what and how information in displayed on the screen of a digital device (Guzzetti, 2015). Thus, people generally use a multitude of digital devices and digital spaces to access OTSs, and this further serves to add to the complexity of the OTS especially within a block and online teaching context. In that, within the block teaching approach, particularly in block 1 and/or the beginning of each block, students and tutors have less time to familiarise themselves with digital spaces; i.e., locating and using new online platforms correctly. This is consistent with the Student Digital Experiences Insight Survey, which highlighted the need for students to be supported in the use of online technologies (Killen and Langer-Crame, 2020). The authors insightfully noted that student's must be supported beyond the level of allowing them to access materials and that they need to see the benefits of engaging and using technology effectively to further their learning.

Spatial practice occurs primarily through students and tutors' digital devices, and so tends to occur frequently, in any location, and even automatically. Through such frequent and consistent use, accessing online teaching spaces can become a habit (Yang, Baldwin and Snelson, 2017), especially when accessed under similar contexts and for similar purposes (Danner, Aarts, and de Vries, 2008). This demand of 'digital connectivity' to constantly update or check (Robinson, 2018) can have both positive and negative outcomes. On the positive side, it can allow the vast majority of students

International Journal of Management and Applied Research, 2021, Vol. 8, No. 1 
to access online course materials whenever they need them and wherever they are (Killen and Langer-Crame, 2020).

Further, an indication that digital activities can engender community building, is that on a national level, $55 \%$ of students worked with their peers in some manner, although this unfortunately highlights that $45 \%$ did not (Killen and Langer-Crame, 2020). This highlights that community building within OTS may be more of a secondary and incidental outcome as opposed to a focus on many online teaching modules. A negative outcome of such connectivity is that it can create a feedback loop between anxiety and uncertainty (e.g., "I need to check my emails in case I miss something important!"). Wherein, people will engage in further checking of information online to reduce anxiety (i.e. repeated checking of emails), which unfortunately only serves to reinforce further checking (Alvi et al., 2018). Such anxieties are entrenched by the 'instant response' culture, where tutors feel increasingly under pressure to be connected all the time and to respond immediately to emails 24 hours a day, 7 days a week(White and Cornu, 2002). This can result in online habits that are consistent in timing, place, and purpose (Wood, Tam and Witt, 2005). The habitual and demanding nature of online spaces (therein OTSs)was succinctly captured by Kosari and Amoori (2018):

"The increasing interpenetration of real and virtual spaces intensifies the stresses day after day and more and more skills are needed to manage interactions in and between these spaces. An individual unable to manage their activities using a laptop or a smartphone, while at home, faces ever-increasing anxiety. [...] It is increasingly related to the management of our emotions and relationships. Real and virtual spaces both result in emotional relationships, which are hard to manage and good skills are required to manage them.” (p. 182)

Tensions in spatial practice can easily occur for students and tutors in the OTS. For example, a common report within sessions on MS Teams, is that students tend to engage in colloquial manner of communication (e.g., use of text speech, emoticons) in text. Similarly, anecdotal evidence suggests from observations at Manchester Met that students choose to communicate via text rather than use voice or video. While research on synchronous video sessions is sparse, a possible suggestion inferred from Gilpin (2020) is that such methods may impact upon the flexibility and convenience that students perhaps expect in online courses. This is in contrast to tutors who generally communicated via video, and then had to read and respond to the text chat of students at the same time. As an insightful colleague at Manchester Met reported: "It helps if you think of yourself as a radio presenter!" In this instance, the communicative habits that students use as a matter of normative practice in online spaces (e.g., social networking sites) overrides the perhaps more formal and academic modes of communication expected by tutors during sessions.

This offers a challenge tutors in blocks of six weeks in length, where the observation was that at Manchester Met students generally kept their cameras off and did not talk. Reasons for this can be shyness, noisy home backgrounds, not wearing appropriate clothes, poor internet connection, and uncomfortable with recording (Yang, Baldwin

International Journal of Management and Applied Research, 2021, Vol. 8, No. 1 
and Snelson, 2017). Such reasons along with the short time within sessions and across the block, makes it difficult for tutors to establish 'video on' and 'talking' as the norm if it is not established. If this does not occur then there is a danger of tutor's simply "covering content" (Nerantzi and Chatzidamianos, 2020). A possible explanation of this is gleaned from a survey of student digital media use, where only $17 \%$ felt like they have been involved in decisions about online teaching technologies (Killen and Langer-Crame, 2020). The authors proposed that providing students the opportunity to contribute, allows all users to benefit. Listening to students in how they want to use the synchronous sessions may help foster a collective sense of community. This perspective is in agreement with the Community of Inquiry (CoI) conceptual framework (Garrison, Anderson, and Archer, 1999), and has been highlighted that community building is key to learning in online courses (Leader-Janssen, Nordness, Swain, and Hagaman, 2016). This also concurs with Nerantzi and Chatzidamianos (2020) who highlighted that we need to consider student's context, their everyday reality, interests and aspirations and how these can be brought into learning to create stimulating experiences.

Tutors will likely have to reinforce these interventions at the beginning of each session and/or block(see Nerantzi and Chatzidamianos, 2020), and model good behaviours themselves in such spaces. Further, rewarding socially those who do speak (while not being overly directive or punitive), with the hope that this encourages (i.e., peer modeling of academic and social behaviours; see Ledford and Wolery, 2013) others to engage in this manner also. Lastly, if we want to consider delivering such interventions, it needs to be reflected in resource implications that provide tutors with sufficient time to put them in place.

\section{Representations of space and the online block teaching space}

Representations of space relate to how space is conceived, represented and constructed (Lefebvre, 1991). It reflects how our mental constructions of a given space are reflected in thought, ideation, planning, and categorisation(Carp, 2008). Representations of space refer to the manner in which we impose meaning and purpose of a given space via abstract and symbolic representations (Lefebvre, 1991).

When applied to an OTS in a block-teaching context, representations of space refer to the manner that the OTS shapes thinking and/or behaviours in physical space. For example, a student thinks, "I have an assessment due but I do not know what I am doing!" and so quickly emails the tutor to ask them what to do. At these moments, the student exists in a blended synthetic Third Space (Kosari and Amoori, 2018), a space that has the characteristics of the other two. Like any space, it comes with its own demands, rules and boundaries, and may even mediate the relationship between two spaces. It is a unique space of meaning making that occurs via the interaction and conflict of the agent with the respective spaces and other agents. Such conflicts are exacerbated as Third Space is distinctive and unique to each actor and/or context (Guzzetti, 2015). In the above example, conflict and dissonance can easily arise through dependency, as the ease of sending the email (as we also discussed in the spatial practice section) about the assessment question can potentially supersede the

International Journal of Management and Applied Research, 2021, Vol. 8, No. 1 
work needed to investigate the question thoroughly, which is a likely expectation of the tutor. Again, the time crunched nature of the block teaching format can exacerbate this. In that, if students have issues with course materials in one week, they only have a limited time to resolve them before the next weeks learning activities and sessions are upon them. For some students, there is a danger that a collapse in their learning autonomy and associated confidence in navigating online spaces can occur. In that, a lack of understanding at the beginning of a block then influences confidence, engagement and persistence to learn in the following week(s).

Considering the time-scrunched nature of a six-week block teaching approach, it highlights the importance for tutors to identify and present key threshold concepts within the learning materials of each module (Nerantzi and Chatzidamianos, 2020). Then, within the online sessions, it is the hope that via student-tutor and studentstudent dialogue, the threshold concepts that are found challenging are discussed, debated and resolved. Thus, if students engage in a meaningful way with their learning, then this has been observed to not only allow them to connect with the subject with their peers(Ragusa and Crampton, 2018). Thus, we concur with the review of Carrillo and Flores (2020) on the topic of online teaching in the current COVID climate. They identified that it was the degree that tutors and students "interact, collaborate and build relationships with other members [in the OTS, which] was a source of satisfaction for students ... and greatly influenced the cohesion of learning communities ... [and] the co-construction of knowledge among participants" (p. 471).

A second observation pertains to 'visible' student engagement within the online block teaching structure, and how do we know when a student is engaging or not. In a faceto-face session, it is generally easier to identify engagement on the levels of physical presence, interaction, and emotional interest. Thus, while students in the online session may actually be engaged across these dimensions, tutors are left in the unfortunate position of not having the usual cues to extract this information, e.g., physical face/emotions, eye contact, body language, etc. In effect, the online space creates more unknowns for the tutor as they attempt to determine the success of the session they are delivering, which as we discussed previously; uncertainty is known to evoke anxiety. This coincides with the observation of tutors at Manchester Met who have experienced uncertainty and anxiety with respect to engagement, interest and depth of learning.

In observations at Manchester Met, it has been noted that some level five (i.e., $2^{\text {nd }}$ year undergraduate) students who did not complete the asynchronous activities (i.e., listen to pre-recorded lectures), were then (unsurprisingly) not prepared for and even complained that they did not understand what was going on in the synchronous sessions. This is consistent with a report on block delivery by Male et al. (2016) who noted that students were consistently underprepared for classes. However, with what we previously discussed with respect to spatial practices and representations of space this is to be somewhat expected. In that, in the traditional face-to-face lecture format, students across level four, five, and six can come to a lecture unprepared, with the expectation that the content of the lecture (i.e., PowerPoint slides) and the tutor(s) will provide the 'learning event.' Recent ISS comments of psychology undergraduate

International Journal of Management and Applied Research, 2021, Vol. 8, No. 1 
students (levels 4, 5, and 6) in block 1 of an online approach at Manchester Met support this. Specifically, it highlighted a general theme that students commented negatively on the degree of independent learning required in the online block teaching format, and wanted more taught content and in-depth learning.

What we observe in a block-teaching context is that some students simply carry their established learning habit from traditional lectures into it. This perhaps identifies the need to target 'preparedness' in level four students (Male, et al., 2016). What we may be observing is the continuation of more directive habits of learning from secondary school into university (Luk, 2005), which without intervention continues throughout their time at university. In effect, they continue to employ a familiar and automatic learning strategy that has been rooted early in their formative education, and then we expect them without sufficient support to replace it with an unfamiliar learning approach. Within the Lefebvrian model, we suggest that students carry pre-existing representations of space from the secondary to the university environment with an expectation of directed learning. This then clashes with the expectations that tutors have in terms of the preparedness and autonomy of students, a discrepancy that is heightened in online block teaching. Potential interventions are to make students aware of the intensive nature of block delivery early in induction, encourage selfmanagement (e.g., prepare for random quizzes) and peer-to-peer learning and collaborations, and for personal tutors to follow upon on the intensive commitment it requires (Male, et al., 2016).

In addition, research by Truta, Parv and Topala (2018) indicated a relationship between limited engagement and early drop-out intentions on a given course. This observation concurs with the findings of Dixon and O'Gorman (2020) who noted that while block teaching allowed tutors to manage their time more efficiently, block teaching may have a negative impact upon student attendance, session preparation, depth of learning, and fatigue among staff. This is likely to be exacerbated when blocks are delivered in succession, and students and staff suffer from fatigue due to the intensiveness of this format (Daniel, 2000). This is an important point, for block teaching to be effective, research has shown that tutors employ a range of teaching approaches, that creates a nurturing learning environment that actively involves the students, within the time constraints and pressures of block teaching (Scott, 1996). However, this yet again demands that tutors be given adequate staff development and preparation time to deliver such sessions.

Further, related to the present discussion on block teaching, was the observation that interventions were more successful when offered in the intention phase of decisionmaking in comparison to before students make the decision to leave a course (Truta, et al., 2018). Consistent with our observation on the importance of community, this shows the need to foster and online environment that encourages positive relationships with our students. We need to create a community where students feel comfortable to ask questions about not only threshold concepts but also that they feel comfortable to share their worries with their tutors. This serves to underline the importance of personal tutors, particularly in the online context, to identify students who are struggling early within each block and to discuss with them their personal situation and learning needs so that the tutor can empower students to engage with 'their' learning. Personal tutors can imbue a sense of learning community and belonging for the

International Journal of Management and Applied Research, 2021, Vol. 8, No. 1 
students that was perhaps missing. Indeed, an intensive approach to personal tutoring on the online Masters Conversion Program in Psychology at MMU, with appropriate workload provision for personal tutoring, has seen the majority of students report positively on their relationship with and need for their personal tutor. Research indicates that an improved sense of community is associated with improvements in student engagement, satisfaction, and persistence (Gilpin, 2020). In a related manner, Kofinas et al. (2017) identified the importance of induction to ensure that students "hit the ground running" to succeed in the block teaching format. This highlights the need for simply designed and easy to navigate online courses, along with clear and ongoing communication between personal tutors, programme and unit leads, and tutors who facilitate the synchronous and asynchronous activities.

\section{Representational space and the online block teaching space}

Representational space relates to the 'lived', produced and reproduced experiences of space (Lefebvre, 1991). This 'lived space' can evoke a sense of meaning and a strong sense of "in-the-moment awareness of being alive or fully present" (Carp, 2008, p. 135). Representational space is not experienced via purely physical properties, but rather an amalgamation of visual, verbal, and/or kinaesthetic symbolism, which we observe in pictures, writing, music, gestures, metaphors, signs or rapt attention (Carp, 2008), that evoke memories and emotions, impose social norms, and can create a strong sense of social belonging (Buser, 2012). The phenomenological experience within representational space is one that is fleeting in nature yet enhances consciousness in the lived moment and/or a retrospective representation.

When applied to an OTS in a block-teaching context, all of these are intrinsically intertwined with an individual's 'lived' experience in those OTSs. Carrillo and Flores (2020) noted the importance of personal experiences within OTS in their review of on online teaching and learning practices in relation to COVID-19(Chatzidamianos and Nerantzi, 2020). They identified themes such as belongingness (e.g., trusting relationships), cohesiveness (e.g., collaboration), and participation (e.g., prioritising social interaction over task completion) as key to establishing a sense of social community in an online block teaching setting. Research also indicates that intensive modes of teaching can also foster bonds between tutors and students and help develop a learning community (Male, et al., 2016).

However, these positives can run contrary to student's actual experience of community when they have to learn online. It can be a lonely experience and disparate from any of the themes identified above, and so may have a learning reality that lack any meaningful connection to the learning outcomes, other students, and tutor expectations (Nerantzi and Chatzidamianos, 2020). Complicating students' interactions with OTSs further, is that the online spaces that students (and tutors to a lesser extent) are familiar with (e.g., social media),can make them all too readily aware of their failure to attain an 'idealized' representation of their self (Nadkarni and Hofmann, 2012). This can result in an ideal-self clash for students, where they are aware that they fail to meet the demands of an online academic space in terms of their own preparation, knowledge and engagement. As stated by Kasza (2017) the "virtual identity [ideal-self] ... often

International Journal of Management and Applied Research, 2021, Vol. 8, No. 1 
seems to dialogue or compete with the real one, constantly reminding us about our limitations or weaknesses ... mainly because often our ... [ideal-self] takes over the existing reality" (p. 48). While this seems rather extreme, a common report at Manchester Met during online sessions is that students tend not to turn their camera on, prefer to write in the text chat than use voice, and some have even expressed more anxiety about presenting online than in a traditional class setting.

However, one should not ignore the fact, that some shy students actually prefer online teaching, as it gives them more time to reflect, and encourages them to engage more. Together, this highlights the inherent complexity of online teaching, where tutors attempt to be inclusive to a spectrum of preferences. As Nerantzi and Chatzidamianos (2020) noted, online teaching has highlighted our need and the pedagogical benefits of connection, togetherness, and distant socialising.

We discussed in the previous section some observations associated with students' engagement and learning motivation. Related to representational space, student engagement/learning motivation has key affective components of "feelings of identification or belonging, and relationships with teachers and peers (for psychological engagement)" (Appleton, Christenson, and Furlong, 2008, p. 372). However, how do we create this within an online blocked teaching format and overcome the previously discussed barriers in spatial practice and representations of space? When engagement and motivation is low, some suggestions are to spend time on socialisation activities (e.g., community building); empowering students to lead activities (e.g., choosing topics of interest, use of break out rooms); deploy interactive technology (e.g., Padlet, quizzes); integrate problem-based learning (PBL; see Wood, 2003), to name but a few. However, as most tutors are already employing such strategies, it is likely that it is the degree of (in)congruence between students and tutors in the areas of spatial practice and representations of space that will largely determine the success of these endeavours. In that, we observe that student engagement in asynchronous activities largely determines the success of the synchronous activities completed in subsequent sessions.

Online teaching emphasises the need for community perhaps even more so than traditional face-to-face sessions. While we can rely on clicks on Moodle or videos or attendance at sessions to inform our opinions on online engagement, they really do not reveal the full experience of the student in the OTS. This is particularly pertinent when a tutor looks at a blank computer screen, with no responding voices and then attempts to engage and decode the silence that they are faced with. The solution is likely not more monitoring and policing but by building communities with strong links between the students, tutors and the learning materials. Indeed, we have seen this on the online Masters Conversion Course in Psychology at Manchester Met, where personal tutors have been provided greater provision in their workload to hold one-to-one and group sessions with students. This has allowed personal tutors to understand where the students are in the learning process, what their learning needs are and design interventions to support their learning while also progressively helping them to become more autonomous and collaborate with their peers.

International Journal of Management and Applied Research, 2021, Vol. 8, No. 1 


\section{Lessons Learnt and Future Research}

Based on this discussion of online block teaching at Manchester Met and the Department of Psychology undergraduate programs specifically, we propose the following guiding principles for practice and avenues of future research.

First, how has Lefebvre's model offered a suitable means to make sense of student and tutor behaviours, thoughts and emotions in an online block-teaching context? We have highlighted that OTSs likely requires greater focus and development on community building than in traditional face-to-face teaching contexts. This is because the human aspect of student engagement is unknown and often hidden behind the veil of the computer screen in online sessions. Thus, community building likely has to be at the forefront on online module design, where links between students and tutors are established and strengthened throughout successive blocks.

Second, we acknowledge that tutors and staff do not operate in isolation in the OTS but rather respond to, interact, and shape the experience of the other. As such, we propose that determining the degree of congruence or incongruence between tutors and students within each arm of Lefebvre's Trialectic may inform those who deliver units on underlying reasons for engagement, persistence, sense of community academic achievement, etc. For example, if students and tutors hold discrepant mental representations - only listening versus talking, respectively - regarding the use of a given teaching space, it is likely that a degree of dissonance, anxiety and even conflict may follow. This points toward an avenue of future research. In that, there is a need to quantify our modified version of Lefebvre's model beyond the present theoretical exposition. Designing questionnaires that tap into each arm of the model, and having both students and tutors complete these would satisfy this. The completion of Likert scale responses, while rudimentary, will empirically quantify the degree of (in)congruence between students and tutors for each aspect of Lefebvre's model and how this relates to metrics (e.g., Internal Student Surveys and National Student Survey) such as student satisfaction, sense of community, engagement, and depth of learning. If validated, this would provide those who lead units/programmes a new means to understand and act upon students' academic performance, tutor anxieties and concerns, and areas of tensions between the two groups. Further, the importance of gender in online spaces generally (e.g., social networking sites) has been previously researched (e.g., Haferkamp et al., 2012), whereas gender differences in OTS has been investigated (e.g., Cuadrado-Garcia et al., 2012) but with little research into the cause of gender differences in the use of the OTS. We propose that the use of the present Lefebvrian model via a questionnaire would allow such a quantitative exposition of this issue and provide a novel and new addition to the literature.

The importance of the inclusivity of the OTS is further is supported by Portugali, Benenson and Omer (1997)who proposed that to reduce dissonance in the perceived or actual use of a given space, their needs to be a change in either spatial location or the intended use of that space. This is consistent with the findings of Truta, Parv and Topala (Truta, et al., 2018) who observed a relationship between limited engagement and early dropout intentions on university courses. As educators, we want to guard against students leaving the OTS (i.e., not attending) and as we cannot remove the

International Journal of Management and Applied Research, 2021, Vol. 8, No. 1 
online feature from a teaching approach dependent on it, we need to ensure that students ascribe and experience a strong sense of personal value and community within the OTS.

Within Figure 1, a potential solution is to employ pedagogical approaches that encourage and draw upon Lefebvre's representational space notion of the 'lived experience.' For example, employing PBL approaches with tasks that require students to work in groups, agreeing roles and responsibilities, and then presenting their findings within sessions (Wood, 2003). Within a block of 6 weeks in length, two PBL activities could occur at weeks three and six. During the intermediate weeks, tutors can answer questions, provide feedback, and reinforce group dynamics and the expected use of the OTS within the block-teaching format. It is important to temper these theoretical expositions with the realities of tutors operating within already overly stretched workloads. This concurs with Nerantzi and Chatzidamianos (2020), who in their recent paper on online block teaching, highlighted the importance of reaching out to students to ask "what works for them" (p. 492) and to utilise this information in subsequent programme or unit or workshop design. Via ownership of the process, this encourages students and tutors to enter what we previously discussed as the Third Space. It is a transformative space with the potential for expanded learning and development of new knowledge, especially if the space and the work carried out within that space "become particularly meaningful to their participants over time" (Gutierrez, 2008, p. 151). This could indirectly deal with issues of spatial practice (i.e., camera on and talking) and representations of space (i.e., discrepant views of students on tutors on the use of the OTS and sessions).

Therefore, while the present circumstances offer a challenge to us all, online block teaching as viewed through the present Lefebvrian analysis can potentially improve the quality of our teaching, students' engagement, depth of students' learning and the nature of student-tutor and student-student dynamics long into the future.

\section{References}

1. Alavi, S. S., Ghanizadeh, M., Mohammadi, M. R., Mohammadi Kalhory, S., Jannatifard, F. and Sepahbodi, G. (2018), "The Survey of Personal and National Identity on Cell Phone Addicts and Non-Addicts", Iranian journal of psychiatry, Vol. 13, No. 1, pp. 15-21.

2. Appleton, J. J., Christenson, S. L., and Furlong, M. J. (2008), "Student engagement with school: Critical conceptual and methodological issues of the construct", Psychology in the Schools, Vol. 45, No. 5, pp. 369-386. https://doi.org/10.1002/pits.20303

3. Bargh, J. A. and McKenna, K. Y. A. (2004), “The Internet and social life", Annual Review of Psychology, Vol. 55, pp. 573-590. https://doi.org/10.1146/annurev.psych.55.090902.141922

4. Boddy, G. W. (1986), Regular vs. compressed semester: A comparison of effectiveness for teaching in higher education, Lincoln: University of Nebraska. [Online]

from:

International Journal of Management and Applied Research, 2021, Vol. 8, No. 1 
"It Helps if You Think of Yourself as a Radio Presenter!" A Lefebvrian Commentary on the Concerns, Conflicts and Opportunities of Online Block Teaching

https://digitalcommons.unl.edu/dissertations/AAI8606958 [Accessed on 4 December 2020].

5. Bouchillon, B. C. (2020), "Social Networking for Interpersonal Life: A Competence-Based Approach to the Rich Get Richer Hypothesis", Social Science Computer Review. https://doi.org/10.1177/0894439320909506

6. Bunce, M. (2008), "The 'leisuring' of rural landscapes in Barbados: New spatialities and the implications for sustainability in small island states", Geoforum, Vol. 39, No. 2, pp. 969-979. https://doi.org/10.1016/j.geoforum.2007.10.005

7. Buser, M. (2012), "The production of space in metropolitan regions: A Lefebvrian analysis of governance and spatial change", Planning Theory, Vol. 11, No. 3, pp. 279-298. https://doi.org/10.1177/1473095212439693

8. Carp, J. (2008). "Ground-Truthing Representations of Social Space: Using Lefebvre's Conceptual Triad", Journal of Planning Education and Research, Vol. 28, No. 2, pp. 129-142. https://doi.org/10.1177/0739456X08324685

9. Carrillo, C. and Flores, M. A. (2020), "COVID-19 and teacher education: a literature review of online teaching and learning practices", European Journal of Teacher Education, Vol. 43, No. 4, pp. 466-487. https://doi.org/10.1080/02619768.2020.1821184

10. Chatzidamianos, G. and Nerantzi, C. (2020), "Stripping the layers of the onion in learning and teaching in HE. Learning and teaching in HE: positive lessons learned from working during a pandemic", Advance Higher Education [Online] Available from: $\quad$ https://www.advance-he.ac.uk/news-and-views/stripping-layers-onionlearning-and-teaching-he [Accessed on 4 December 2020].

11. Daniel, E. L. (2000), "A Review of Time-shortened Courses across Disciplines", College Student Journal, Vol. 34, No. 2, pp. 298-308

12. Danner, U. N., Aarts, H., and de Vries, N. K. (2008), "Habit vs. intention in the prediction of future behaviour: The role of frequency, context stability and mental accessibility of past behaviour", British Journal of Social Psychology, Vol. 47, No. 2, pp. 245-265. https://doi.org/10.1348/014466607x230876

13. Davies, M. (2006), "Intensive Teaching Formats: A Review", Issues in Educational Research, Vol. 16, No. 1, pp. 1-20.

14. Dickson, K., Bird, K., Newman, M., and Kalra, N. (2010), "What is the effect of block scheduling on academic achievement? A systematic review", In: Research Evidence in Education Library. London: EPPI-Centre, Social Science Research Unit, Institute of Education, University of London.

15. Dixon, L., and O'Gorman, V. (2020), "Block teaching - exploring lecturers' perceptions of intensive modes of delivery in the context of undergraduate education", Journal of Further and Higher Education, Vol. 44, No. 5, pp. 583-595. https://doi.org/10.1080/0309877x.2018.1564024

16. Garrison, D. R., Anderson, T., and Archer, W. (1999), "Critical Inquiry in a TextBased Environment: Computer Conferencing in Higher Education", The Internet

International Journal of Management and Applied Research, 2021, Vol. 8, No. 1 
"It Helps if You Think of Yourself as a Radio Presenter!" A Lefebvrian Commentary on the Concerns, Conflicts and Opportunities of Online Block Teaching

and Higher Education, Vol. 2, No. 2, pp. 87-105. https://doi.org/10.1016/S10967516(00)00016-6

17. Gilpin, S. (2020), “A Framework for Fostering Emerging Online Learner Persistence: The Role of Asynchronous and Synchronous Discussions", Journal of Teaching and Learning, Vol. 14, No. 1, pp. 29-42. https://doi.org/10.22329/jtl.v14i1.6253

18. Gonzales, A. L. and Hancock, J. T. (2011), "Mirror, Mirror on my Facebook Wall: Effects of Exposure to Facebook on Self-Esteem", Cyberpsychology Behavior and Social Networking, Vol. 14, No. 1-2, pp. 79-83. https://doi.org/10.1089/cyber.2009.0411

19. Gutierrez, K. D. (2008), "Developing a sociocritical literacy in the Third Space", Reading Research Quarterly, Vol. 43, No. 2, pp. 148-164. https://doi.org/10.1598/rrq.43.2.3

20. Guzzetti, B. (2015), Handbook of Research on the Societal Impact of Digital Media, USA: IGI Global.

21. International Bureau of Education (2020), Block Teaching. [Online] Available from: http://www.ibe.unesco.org/en/glossary-curriculum-terminology/b/blockteaching [Accessed on 4 December 2020].

22. JISC (2020), Learning and teaching reimagined Change and challenge for students, staff and leaders, Bristol: JISC [Online] Available from: https://www.jisc.ac.uk/sites/default/files/ltr-report-change-and-challenge-forstudents-staff-and-leaders-aug-2020.pdf [Accessed on 4 December 2020].

23. Kasza, J. (2017), “Post Modern Identity: “In Between” Real And Virtual”. World Scientific News, Vol. 78, pp. 41-57.

24. Katz, J. E. and Crocker, E. T. (2015), "Selfies and Photo Messaging as Visual Conversation: Reports from the United States, United Kingdom and China", International Journal of Communication, Vol. 9, pp. 1861-1872.

25. Kaya, S. and Aksu, M. (2016), "The advantages and disadvantages of block scheduling as perceived by middle school students", Journal of Educational and Instructional Studies in the World, Vol. 6, No. 1, pp. 50-59.

26. Killen, C. and Langer-Crame, M. (2020), Student digital experience insights survey 2020: UK higher education findings. Bristol: JISC [Online] Available from: https://www.jisc.ac.uk/sites/default/files/student-dei-he-report-2020.pdf [Accessed on 4 December 2020].

27. Kofinas, A., Bentley, Y., Minett-Smith, C. and Cao, G. M. (2017), "Block Teaching as the Basis for an Innovative Redesign of the PG Suite of Programmes in University of Bedfordshire Business School", presented at the 3rd International Conference on Higher Education Advances, 21-23 June 2017, Valencia: Polytechnic University of Valencia Congress. https://doi.org/10.4995/HEAd17.2017.5379

International Journal of Management and Applied Research, 2021, Vol. 8, No. 1 
"It Helps if You Think of Yourself as a Radio Presenter!" A Lefebvrian Commentary on the Concerns, Conflicts and Opportunities of Online Block Teaching

28. Kosari, M. and Amoori, A. (2018), "Third space: The Trialectics of the Real, Virtual and Blended Spaces", Journal of Cyberspace Studies, Vol. 2, No. 2, pp. 163-185. https://doi.org/10.22059/jcss.2018.258274.1019

29. Leader-Janssen, E. M., Nordness, P. D., Swain, K. D., and Hagaman, J. L. (2016), "Students' Perceptions of an Online Graduate Program in Special Education for Emotional and Behavioral Disorders", Teacher Education and Special Education, Vol. 39, No. 4, pp. 246-258. https://doi.org/10.1177/0888406416637411

30. Ledford, J. R. and Wolery, M. (2013), "Peer Modeling of Academic and Social Behaviors During Small-Group Direct Instruction", Exceptional Children, Vol. 79, No. 4, pp. 439-458. https://doi.org/10.1177\%2F001440291307900404

31. Lefebvre, H. (1991). The Production of Space, translated by Nicholson-Smith, D. UK: Wiley-Blackwell.

32. Leston-Bandeira, C. (2020), "Online teaching works best when a learning community is nurtured", Political Studies Association - Blog. [Online] Available from: https://www.psa.ac.uk/psa/news/online-teaching-works-best-when-learningcommunity-nurtured [Accessed on 4 December 2020].

33. Loton, D., Stein, C., Parker, P., and Weaven, M. (2020), "Introducing block mode to first-year university students: a natural experiment on satisfaction and performance", Studies in Higher Education, pp. 1-23. https://doi.org/10.1080/03075079.2020.1843150

34. Luk, H. S. (2005), "The gap between secondary school and university mathematics", International Journal of Mathematical Education in Science and Technology, Vol. 36, No. 2-3, pp. 161-174. https://doi.org/10.1080/00207390412331316988

35. Male, S., C. , Baillie, P., Hancock, J., Leggoe, C., MacNish, S., Crispin, S., Ranmuthugala, D. and Alam, F. (2016). Intensive Mode Teaching Guide. [Online] Available https://www.staff.uwa.edu.au/_data/assets/pdf_file/0004/2886052/IMT-GuideRecommendations-v4b-for-web.pdf [Accessed on 4 December 2020].

36. Messina, R. C. (1996), Power package: An alternative to traditional course scheduling, ERIC Document Reproduction Service No. ED 396787.

37. Nadkarni, A. and Hofmann, S. G. (2012), "Why Do People Use Facebook?" Personality and individual differences, Vol. 52, No. 3, pp. 243-249. https://doi.org/10.1016/j.paid.2011.11.007

38. Nerantzi, C. and Chatzidamianos, G. (2020), "Moving to Block Teaching during the COVID-19 Pandemic", International Journal of Management and Applied Research, Vol. 7, No. 4, pp. 482-495. https://doi.org/10.18646/2056.74.20-034

39. Nerantzi, C. (2017), Towards a framework for cross-boundary collaborative open learning in cross-institutional academic development, $\mathrm{PhD}$ Thesis, UK: Edinburgh Napier University. [Online] Available from: https://www.napier.ac.uk/ /media/worktribe/output-1025583/towards-aframework-for-cross-boundary-collaborative-open-learning-for.pdf [Accessed on 4 December 2020].

International Journal of Management and Applied Research, 2021, Vol. 8, No. 1 
"It Helps if You Think of Yourself as a Radio Presenter!" A Lefebvrian Commentary on the Concerns, Conflicts and Opportunities of Online Block Teaching

40. Parkin, S., and Coomber, R. (2011), "Public injecting drug use and the social production of harmful practice in high-rise tower blocks (London, UK): A Lefebvrian analysis", Health and Place, Vol. 17, No. 3, pp. 717-726. https://doi.org/10.1016/j.healthplace.2011.02.001

41. Portugali, J., Benenson, I., and Omer, I. (1997), "Spatial cognitive dissonance and sociospatial emergence in a self-organizing city", Environment and Planning BPlanning and Design, Vol. 24, No. 2, pp. 263-285. https://doi.org/10.1016/j.healthplace.2011.02.00110.1068/b240263

42. Proctor, C. (2017), "Conditions of Worth (Rogers)", In V. Zeigler-Hill and T. K. Shackelford (Eds.), Encyclopedia of Personality and Individual Differences, Cham: Springer International Publishing. https://doi.org/10.1007/978-3-31924612-3_1459

43. Ragusa, A. T., and Crampton, A. (2018), "Sense of connection, identity and academic success in distance education: sociologically exploring online learning environments", Rural Society, Vol. 27, No. 2, pp. 125-142. https://doi.org/10.1080/10371656.2018.1472914

44. Robinson, L. (2018), "The identity curation game: digital inequality, identity work, and emotion management", Information, Communication and Society, Vol. 21, No. 5, pp. 661-680. https://doi.org/10.1080/1369118X.2017.1411521

45. Saunders, C., Rutkowski, A. F., van Genuchten, M., Vogel, D., and Orrego, J. M. (2011), "Virtual space and place: Theory and test", MIS Quarterly, Vol. 35, No. 4, pp. 1079-1098.

46. Scott, P. A. (1996), "Attributes of High-Quality Intensive Course Learning Experiences: Student Voices and Experiences", College Student Journal, Vol. 30, pp. 69-77.

47. Sewagegn, A. A. And Diale, B. M. (2019), "Modular/Block teaching: practices and challenges at higher education institutions of Ethiopia", Teaching in Higher Education, pp. 1-14. https://doi.org/10.1080/13562517.2019.1681391

48. Swain, M. (2016), "Block teaching and the three A's: attendance, attainment and attitudes", Innovation in Practice, Vol. 10, No. 1, pp. 33-38. https://doi.org/10.24377/LJMU.iip.vol10iss1article57

49. Tiidenberg, K. and Cruz, E. G. (2015), "Selfies, Image and the Re-making of the Body", Body and Society, Vol. 21, No. 4, pp. 77-102. https://doi.org/10.1177/1357034x15592465

50. Truta, C., Parv, L., and Topala, I. (2018), "Academic Engagement and Intention to Drop Out: Levers for Sustainability in Higher Education”, Sustainability, Vol. 10, No. 12, 4637. https://doi.org/10.3390/su10124637

51. Urry, J. (1995), Consuming Places. London: Routledge.

52. Warren, T. (2016), "Microsoft Teams launches to take on Slack in the workplace", The Verge. [Online] Available from: https://www.theverge.com/2016/11/2/13497992/microsoft-teams-slack-competitorfeatures [Accessed on 4 December 2020].

International Journal of Management and Applied Research, 2021, Vol. 8, No. 1 
"It Helps if You Think of Yourself as a Radio Presenter!" A Lefebvrian Commentary on the Concerns, Conflicts and Opportunities of Online Block Teaching

53. White, B. and Cornu, R. L. (2002), "Email Reducing Stress for Student Teachers", In D. Watson and J. Andersen (Eds.), Networking the Learner: Computers in Education. Boston, MA: Springer US. pp. 671-679

54. Wood, D. F. (2003), "Problem based learning", British Medical Journal, Vol. 326, No. 7384, pp. 328-330. https://doi.org/10.1136/bmj.326.7384.328

55. Wood, W., Tam, L., and Witt, M. G. (2005), "Changing circumstances, disrupting habits", Journal of Personality and Social Psychology, Vol. 88, No. 6, pp. 918933. https://doi.org/10.1037/0022-3514.88.6.918

56. Yang, D., Baldwin, S., and Snelson, C. (2017), "Persistence factors revealed: students' reflections on completing a fully online program", Distance Education, Vol. 38, No. 1, pp. 23-36. https://doi.org/10.1080/01587919.2017.1299561

International Journal of Management and Applied Research, 2021, Vol. 8, No. 1 